Review

\title{
Visions of Sustainability in Bioeconomy Research
}

\section{Swinda F. Pfau ${ }^{1, *}$, Janneke E. Hagens ${ }^{1}$, Ben Dankbaar ${ }^{1,2}$ and Antoine J. M. Smits ${ }^{1}$}

1 Institute for Science, Innovation and Society, Faculty of Science, Radboud University Nijmegen, P.O. Box 9010, Nijmegen 6500 GL, The Netherlands; E-Mails: j.hagens@science.ru.nl (J.E.H.); B.Dankbaar@fm.ru.nl (B.D.); a.smits@science.ru.nl (A.J.M.S.)

2 Institute for Management Research, Radboud University Nijmegen, P.O. Box 9108, Nijmegen $6500 \mathrm{HK}$, The Netherlands

* Author to whom correspondence should be addressed; E-Mail: s.pfau@science.ru.nl; Tel.: +31-24-365-2684.

Received: 23 January 2014; in revised form: 25 February 2014 / Accepted: 27 February 2014 / Published: 6 March 2014

\begin{abstract}
The rise of the bioeconomy is usually associated with increased sustainability. However, various controversies suggest doubts about this assumed relationship. The objective of this paper is to identify different visions and the current understanding of the relationship between the bioeconomy and sustainability in the scientific literature by means of a systematic review. After a search in several databases, 87 scientific journal articles were selected for review. Results show that visions about the relationship between bioeconomy and sustainability differ substantially. Four different visions were identified, including: (1) the assumption that sustainability is an inherent characteristic of the bioeconomy; (2) the expectation of benefits under certain conditions; (3) tentative criticism under consideration of potential pitfalls; and (4) the assumption of a negative impact of the bioeconomy on sustainability. There is considerable attention for sustainability in the scientific bioeconomy debate, and the results show that the bioeconomy cannot be considered as self-evidently sustainable. In further research and policy development, good consideration should therefore be given to the question of how the bioeconomy could contribute to a more sustainable future. Furthermore, it is stressed that the bioeconomy should be approached in a more interdisciplinary or trans-disciplinary way. The consideration of sustainability may serve as a basis for such an approach.
\end{abstract}

Keywords: sustainability; bioeconomy; biomass 


\section{Introduction}

The development of the bioeconomy has recently received increasing attention, both in science and policy. In policy documents, the transition towards a bioeconomy is regularly associated with increased sustainability [1-3]. However, various controversies in scientific and public debates suggest doubts as to whether such a transition will necessarily lead to a better, more sustainable future. Frequently mentioned problems are the competition between food and fuel production and the negative effects of land use change. The goal of this paper is to give a systematic overview of the way sustainability is addressed in the scientific literature about the bioeconomy.

To the best of our knowledge, no review about the scientific debate has been published to date. Some papers deal with the effects of the bioeconomy on sustainability, but mostly focus on specific elements of the bioeconomy, such as biorefineries [4-6]. Others review the role of sustainability in policy documents regarding the bioeconomy [7-9]. Altogether, they stress the importance of considering sustainability when it comes to the bioeconomy. However, none of these papers reflects on the variety of visions about sustainability in the scientific literature.

In this paper, we provide an overview of the way the relationship between sustainability and the bioeconomy is dealt with in the scientific literature. This will help to better understand the underlying visions of sustainability in bioeconomy research. Furthermore, we present an overview of the specific issues raised in the literature with regard to sustainability in the bioeconomy, providing focus points for further research and policy development. Section 2 describes our methodology. In Section 3, we present the results, first in the form of a bibliographic analysis, then distinguishing different visions on the relation between the bioeconomy and sustainability, closing with some general observations resulting from our review. We further discuss our findings in Section 4 with special attention for the conditions under which the bioeconomy might be sustainable. Section 5 concludes with some directions for future research.

\section{Methodology}

The approach of this paper is to systematically review the scientific literature about the bioeconomy and describe how the authors address the concept of sustainability in context with the bioeconomy. Following Fink [10] and Stechemesser et al. [11], we take a four-step approach for our literature review. The first step is the selection of research questions, databases and search terms. The second step is the application of screening criteria to identify relevant literature. The third step is the execution of the review itself, analyzing the content of the selected literature based on the research question. Finally, findings are synthesized and described.

There are various definitions of the bioeconomy. Some authors consider all biotechnological advances that contribute to solving global problems as part of the bioeconomy. Others focus on either biotechnology in the life sciences or the application of biomass as a replacement of fossil materials. In this paper, we will concentrate on the latter group of publications. The bioeconomy is generally defined in these papers as an economy in which all (or most) fossil sources used for various forms of consumption and production are replaced by biomass resources. In some policy documents and publications, the term "bio-based economy" rather than bioeconomy is used. Although it has been 
argued that the two are not identical [9], we have treated the terms as interchangeable for the purposes of our review, because other authors do not follow this distinction consistently.

We have not limited ourselves to specific scientific disciplines. The bioeconomy has been studied in many different disciplines from many different angles. As such, it is a typically multi-disciplinary subject. In multi-disciplinary research, a certain issue is addressed by more than one discipline, each following different goals and producing disciplinary knowledge. In interdisciplinary research, multiple disciplines address a certain issue together, sharing knowledge and striving for joint knowledge production. In trans-disciplinary settings, scientific knowledge from multiple disciplines is integrated with input from societal stakeholders for joint knowledge production [12].

\subsection{Selecting Research Questions, Search Terms and Databases}

To create a complete picture of how sustainability is addressed, a broad research question for the reviewing process was chosen: "How do scientific papers relate the concept of bioeconomy to sustainability?" Based on this question, two main topics were identified for this review: bioeconomy and sustainability. Since the literature about the bioeconomy was supposed to be analyzed regarding their use of the sustainability concept, the bioeconomy was considered as a primary and sustainability as a secondary topic. For "bioeconomy", various synonyms and spellings have been used as search terms: "bioeconomy", "bio economy", "bio-economy", "biobased economy", "bio based economy", "bio-based economy", "biomass based economy" and "biomass-based economy". For "sustainability", the notation, sustainab* has been used as a search term in order to also cover "sustainable" and "sustainable development".

Because the bioeconomy is a multi-disciplinary subject, we chose multiple databases in order to cover a broad range of literature that might address the bioeconomy. Five databases from the fields of natural and environmental sciences, economics and social sciences were chosen: Thomson Reuters Web of Science [13], Scirus [14], ScienceDirect [15], EconLit [16] and the International Bibliography of the Social Sciences [17].

In accordance with the choice of the bioeconomy as the primary topic and sustainability as the secondary topic, the search was conducted searching for the primary search terms in the topic (or title, keywords and abstract, depending on the database) and for the secondary search terms in the full texts or topic (in the Web of Science, full text cannot be chosen). For each search, a combination of all search terms was used, differentiating between the bioeconomy search terms with the Boolean phrase, OR, and between the bioeconomy and sustainability search terms with AND.

\subsection{Application of Screening Criteria}

Figure 1 shows the methods and results of the literature selection based on practical screening criteria. The database search (last conducted on 3 June 2013) resulted in 1373 hits. Since the bioeconomy concept is relatively recent, no limitations to publication dates were made. In a first refinement, the results were reduced to academic journal papers, reviews and conference proceedings in order to focus on the scientific debate about the bioeconomy. In order to give a comprehensive overview of the scientific discourse, neither limitations regarding methodology (i.e., including, for example, empirical, as well as conceptual publications), nor quality criteria (e.g., journal rankings) were made. This way, 
also newer journals that have not been ranked yet could be taken into account. Following this refinement, duplicates resulting from the searches in different databases were eliminated. The resulting 165 papers were screened for their relevance according to two selection questions: (1) Do the bioeconomy search terms in the document regard the use of biomass (our focus)? (2) Does the paper make a substantive connection between the two central concepts?

Since databases do not cover all publications, it was decided to include additional literature, provided that it fulfilled the screening criteria. These papers were selected from previously identified literature and from screening the reference lists of the publications found in the database search. This resulted in an additional 11 papers. In total, 87 publications were selected for review. While these publications are assumed to represent a significant proportion of the relevant literature on the concepts of bioeconomy and sustainability, it is still possible that some work has not been identified. Nevertheless, we are confident that these publications provide a rather complete coverage of scientific contributions to the debate.

Figure 1. The methods and results of the literature selection.

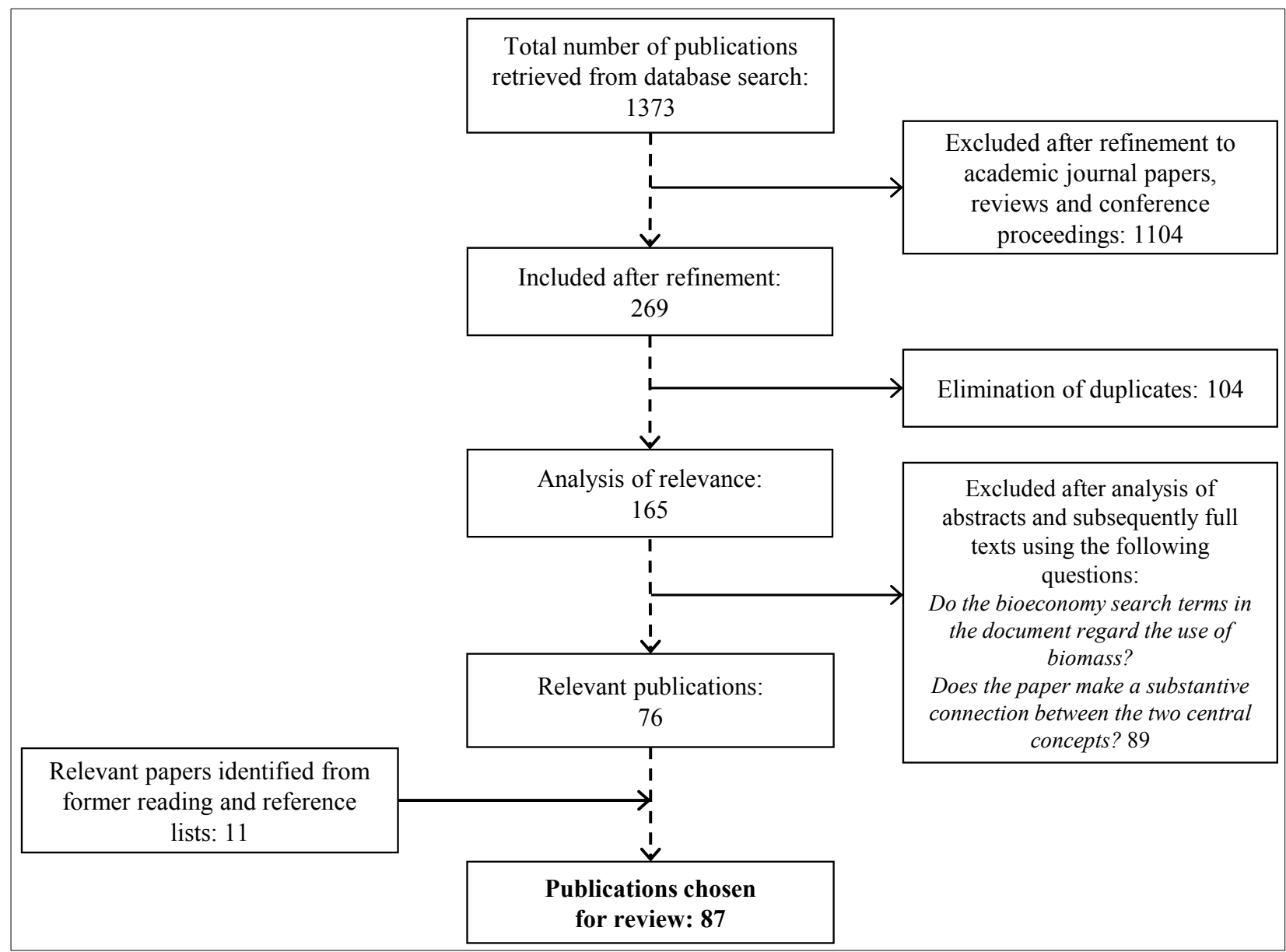

\subsection{Reviewing Process}

As the first step, a bibliographic analysis was conducted. The results are presented in Section 3.1. In order to display the range of topics addressed in the publications, the research domains covered in the papers were analyzed. Initially, all author keywords were grouped into topics, for example representing 
technical aspects (e.g., processing techniques and resource production) or consequences (e.g., environmental or social impacts). For publications that do not offer author keywords important, phrases from titles and abstracts were allocated to domains accordingly. Finally, the most important research domain was determined for each publication, based on the number of keywords or phrases per domain.

For the reviewing process regarding our main research question, the qualitative data analysis (QDA) software package, ATLAS.ti (version 7, [18]), has been used to enable a systematic and consistent approach of analyzing the publications. This approach proved to be useful to identify the various topics and visions related to our research question. The analysis was conducted inductively, marking relevant text passages with codes. In a later stage, the codes were combined into categories according to similar visions on the research topic. The categories and their characteristics are presented in Section 3.2. Furthermore, the codes provided an overview of all issues regarding the sustainability of the bioeconomy addressed in the reviewed publications. The results are presented in Sections 3.2 and 3.3.

The fourth step of the reviewing process - the synthesis of findings — is described and discussed in the following sections.

\section{Results}

The results of this review are presented in three subsections. First, we will show the results of the bibliographic analysis. Then, we will present the different visions on the relation between the bioeconomy and sustainability that can be found in the reviewed literature. Finally, we will provide some general observations resulting from our review. All papers selected for review are presented in alphabetical order in Table 1, showing the respective research domain and category, as defined in Sections 3.1 and 3.2.

Table 1. Publications selected for review in alphabetical order. Per article, the publishing journal, research domain and category (as defined in Sections 3.1 and 3.2) are stated.

\begin{tabular}{|c|c|c|c|}
\hline Reference & Journal & Research domain & Category \\
\hline Alvarenga et al. [19] & Ecological Indicators & Resources & II \\
\hline Arancibia [20] & Technology in Society & Social & IV \\
\hline Barney et al. [21] & Biomass and Bioenergy & Resources & IV \\
\hline Bartolini et al. [22] & Energy Policy & Policies & IV \\
\hline Becker et al. [23] & Energy Policy & Resources & II \\
\hline Benning et al. [24] & The Plant Journal & Resources & II \\
\hline Bergmann et al. [25] & Renewable and Sustainable Energy Reviews & Resources & I \\
\hline Binder et al. [26] & Energy and Environmental Science & Processing and Technology & II \\
\hline Boehlje et al. [27] & $\begin{array}{l}\text { International Food and Agribusiness } \\
\text { Management Review }\end{array}$ & Economics & II \\
\hline Bramsiepe et al. [28] & Chemical Engineering and Processing & Processing and Technology & II \\
\hline Brehmer et al. [29] & Biofuels, Bioproducts and Biorefining & Resources & II \\
\hline Brehmer et al. [30] & Biomass and Bioenergy & Resources & II \\
\hline Bruins et al. [31] & Biofuels, Bioproducts and Biorefining & Processing and Technology & $\mathrm{I}$ \\
\hline Brunori [32] & EuroChoices & Policies & III \\
\hline Centi et al. [33] & Catalysis Today & Processing and Technology & II \\
\hline Charlton et al. [34] & Chemical Engineering Research and Design & Processing and Technology & II \\
\hline Chen [35] & Chinese Journal of Biotechnology & Processing and Technology & $\mathrm{I}$ \\
\hline Chisti [4] & Biofuels, Bioproducts and Biorefining & Environmental impact & II \\
\hline
\end{tabular}


Table 1. Cont.

\begin{tabular}{|c|c|c|c|}
\hline Reference & Journal & Research domain & Category \\
\hline Cichocka et al. [36] & Journal of Biotechnology & Research and Development & $\mathrm{I}$ \\
\hline De Jong et al. [37] & Biofuels, Bioproducts and Biorefining & Processing and Technology & II \\
\hline De Meester et al. [5] & Biofuels, Bioproducts and Biorefining & Environmental impact & II \\
\hline Dubois [38] & Current Opinion in Environmental Sustainability & Resources & II \\
\hline Dusselier et al. [39] & Energy and Environmental Science & Processing and Technology & II \\
\hline Ferdinands et al. [40] & Current Opinion in Environmental Sustainability & Resources & IV \\
\hline FitzPatrick et al. [41] & Bioresource Technology & Processing and Technology & II \\
\hline Galvez et al. [42] & Agriculture, Ecosystems \& Environment & Environmental impact & II \\
\hline Hardy [43] & Trends in New Crops and New Uses & Policies & $\mathrm{I}$ \\
\hline Hatti-Kaul [44] & Crop Science & Processing and Technology & II \\
\hline Hoefnagels et al. [45] & Energy Policy & Economics & II \\
\hline Huang [46] & Botanical Journal of the Linnean Society & Environmental impact & II \\
\hline Jenkins [47] & Biofuels, Bioproducts and Biorefining & Processing and Technology & $\mathrm{I}$ \\
\hline Jordan et al. [48] & Science & Resources & II \\
\hline Junginger et al. [49] & Biomass and Bioenergy & Economics & II \\
\hline Keegan et al. [50] & Biofuels, Bioproducts and Biorefining & Processing and Technology & II \\
\hline Keijsers et al. [51] & Carbohydrate Polymers & Resources & II \\
\hline Kgathi et al. [52] & Energy Policy & Social & II \\
\hline Kircher [53] & Biofuels, Bioproducts and Biorefining & Policies & II \\
\hline Kitchen et al. [54] & Local Environment & Social & IV \\
\hline Krigsten et al. [55] & The Forestry Chronicle & Resources & II \\
\hline Landeweerd et al. [56] & Interface Focus & Resources & III \\
\hline Langeveld et al. [57] & Crop Science & Research and Development & III \\
\hline Lehtonen et al. [58] & Environment, Development and Sustainability & Economics & II \\
\hline Levidow et al. [59] & Science, Technology \& Human Values & Research and Development & IV \\
\hline Liu [60] & Biotechnology Advances & Processing and Technology & II \\
\hline Liu et al. [61] & Biotechnology Advances & Processing and Technology & II \\
\hline Lorenz et al. [62] & Trends in Biotechnology & Processing and Technology & II \\
\hline Marsden [63] & Sustainability Science & Social & IV \\
\hline Mathews [64] & Biofuels, Bioproducts and Biorefining & Policies & II \\
\hline Mathews [65] & Biofuels, Bioproducts and Biorefining & Resources & II \\
\hline Müller et al. [66] & Journal of Biotechnology & Processing and Technology & II \\
\hline Murray et al. [67] & New Biotechnology & Resources & II \\
\hline Navia et al. [68] & Waste Management \& Research & Processing and Technology & $\mathrm{I}$ \\
\hline Nuss et al. [69] & $\begin{array}{l}\text { The International Journal of Life Cycle } \\
\text { Assessment }\end{array}$ & Processing and Technology & III \\
\hline Osseweijer et al. [70] & Genomics, Society and Policy & Social & II \\
\hline Paula et al. [71] & $\begin{array}{l}\text { Journal of Agricultural and Environmental } \\
\text { Ethics }\end{array}$ & Social & III \\
\hline Ponte [72] & Science as Culture & Social & IV \\
\hline Preisig et al. $[73]$ & Energy Procedia & Research and Development & II \\
\hline Puddister et al. [74] & The Forestry Chronicle & Resources & II \\
\hline Raghu et al. [75] & Current Opinion in Environmental Sustainability & Environmental impact & II \\
\hline
\end{tabular}


Table 1. Cont.

\begin{tabular}{|c|c|c|c|}
\hline Reference & $\begin{array}{r}\text { Journal } \\
\end{array}$ & Research domain & Category \\
\hline Richardson [76] & $\begin{array}{l}\text { Environment and Planning C: } \\
\text { Government and Policy }\end{array}$ & Policies & IV \\
\hline Rossi et al. [77] & Biomass and Bioenergy & Social & IV \\
\hline Rüsch gen. Klaas et al. [78] & ChemSusChem & Processing and Technology & II \\
\hline Sanders et al. [79] & Energies & Economics & II \\
\hline Schmid et al. [80] & Bio-based and Applied Economics & Social & III \\
\hline Sheppard et al. [81] & $\begin{array}{l}\text { Current Opinion in Environmental } \\
\text { Sustainability }\end{array}$ & Environmental impact & IV \\
\hline Sheppard et al. [82] & $\begin{array}{l}\text { Current Opinion in Environmental } \\
\text { Sustainability }\end{array}$ & Environmental impact & III \\
\hline Sheppard et al. [83] & $\begin{array}{l}\text { Current Opinion in Environmental } \\
\text { Sustainability }\end{array}$ & Environmental impact & IV \\
\hline Smyth et al. [84] & AgBioForum & Social & II \\
\hline Smyth et al. [85] & AgBioForum & Social & II \\
\hline Spiertz [86] & European Journal of Agronomy & Resources & II \\
\hline Sultana [87] & Biomass and Bioenergy & Resources & II \\
\hline Tanksale et al. [88] & $\begin{array}{l}\text { Renewable and Sustainable Energy } \\
\text { Reviews }\end{array}$ & Processing and Technology & I \\
\hline Templer et al. [89] & Interface Focus & Research and Development & III \\
\hline Ten Bos et al. [90] & Carbohydrate Polymers & Research and Development & III \\
\hline Tsiropoulos et al. [91] & Journal of Cleaner Production & Processing and Technology & $\mathrm{I}$ \\
\hline Vaaje-Kolstad et al. [92] & Science & Processing and Technology & II \\
\hline Van Dam et al. [93] & Industrial Crops and Products & Resources & II \\
\hline Vaneeckhaute et al. [94] & Water, Air, \& Soil Pollution & Processing and Technology & II \\
\hline Vaneeckhaute et al. [95] & Biomass and Bioenergy & Environmental impact & $\mathrm{I}$ \\
\hline Vaneeckhaute et al. [96] & Biomass and Bioenergy & Environmental impact & II \\
\hline Vanholme et al. [97] & Frontiers in plant science & Processing and Technology & II \\
\hline Vitasari et al. [98] & Bioresource Technology & Processing and Technology & II \\
\hline Voll et al. [99] & Biofuels, Bioproducts and Biorefining & Processing and Technology & III \\
\hline Wellisch et al. [6] & Biofuels, Bioproducts and Biorefining & Environmental impact & II \\
\hline Wesseler et al. [100] & AgBioForum & Environmental impact & II \\
\hline Zhang et al. [101] & $\begin{array}{l}\text { Current Opinion in Chemical } \\
\text { Engineering }\end{array}$ & Processing and Technology & I \\
\hline Zilbermann et al. [102] & AgBioForum & Processing and Technology & $\mathrm{I}$ \\
\hline
\end{tabular}

\subsection{Bibliographic Analysis}

As described in Section 2.2, 87 papers were chosen for review. Figure 2 shows the spread of the papers over time, presenting the numbers of papers published per year. It stands out that all publications are relatively recent, the oldest one being from 2002. Apart from this oldest paper, all have been published within the last ten years. This shows that the consideration of sustainability in the bioeconomy debate is a relatively new topic. Furthermore, it stands out that the number of publications has increased strongly: from 2002-2007, only 0-2 papers were published per year, which increased to 
21 in 2012. Since the papers were selected in June, 2013, the total number for the year 2013 is unclear, but the result of just the first half-year, 17 papers, suggests that a further increase in numbers can be expected. The strong increase in publications indicates a rising attention for the topic.

Figure 2. Number of papers reviewed published per year.

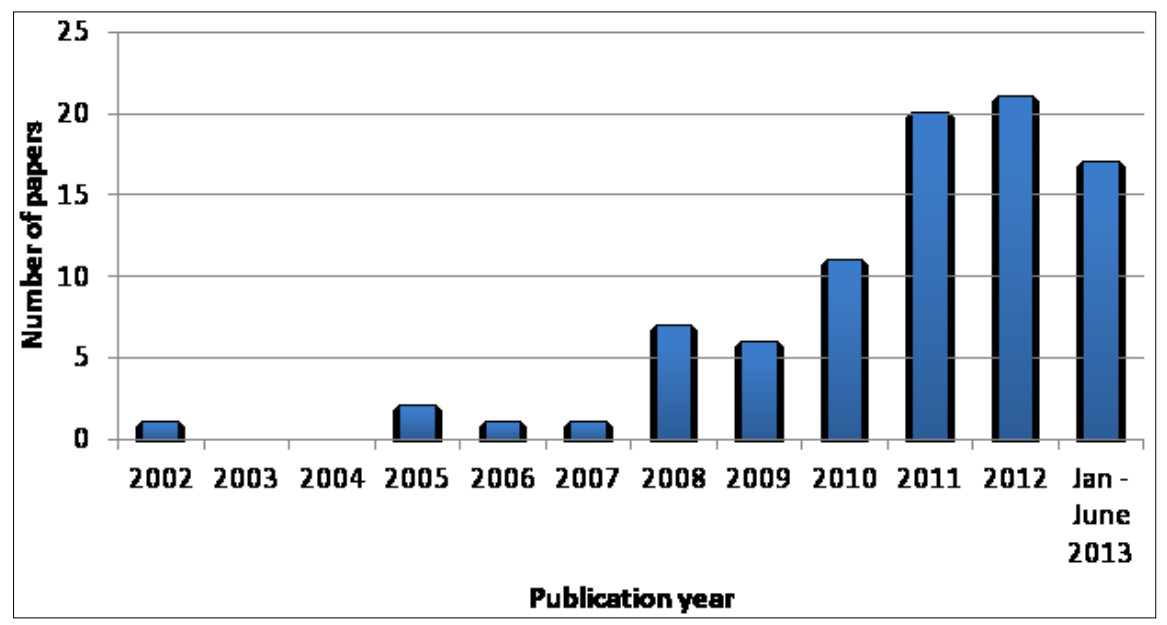

Figure 3 shows the research domains regarding the bioeconomy addressed by the reviewed papers. Seven research domains were identified. Papers falling under the domain "Processing and Technology" mainly describe processing techniques for the conversion of biogenic resources, production pathways for potential bio-products or technology strategies, such as the design of biorefineries. The second domain, "Resources", is comprised of papers discussing the choice and production of biomass resources. Next to the potentials of different feedstock and other biomass sources, also, other aspects, such as land use efficiency and (agricultural) production yields, are discussed. The majority of publications belong to these first two domains, which are both of a relatively technical nature. Other domains of the bioeconomy were addressed less often and were captured under the headings "Environmental Impacts" (e.g., biosecurity), "Social aspects" (e.g., food security), "Policies" (e.g., agricultural or industrial policies), "Research and Development" agendas (e.g., research programs) and "Economics" (e.g., regional economies).

Figure 3. Research domains regarding the bioeconomy and their occurrence in the reviewed papers.

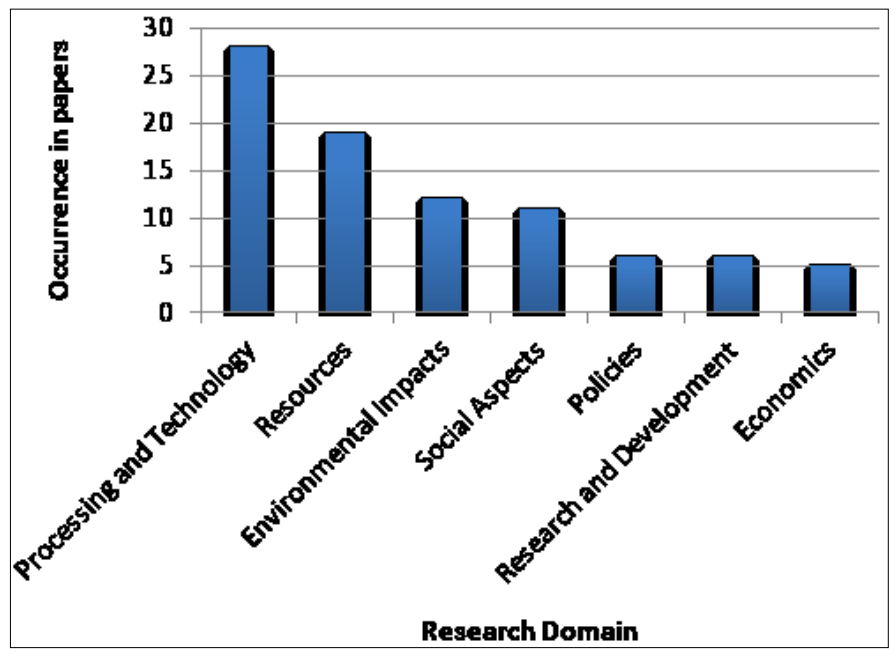




\subsection{Sustainability and the Bioeconomy}

The papers selected for review mention sustainability in some context with the bioeconomy. However, the way sustainability is addressed in these publications differs strongly. Based on these differences, the publications were grouped into four categories that reflect their presumptions of the relation between sustainability and the bioeconomy. The categories are based on descriptions of three important aspects of this relation, which were identified during the review process: contributions of the bioeconomy to sustainable development, conditions or requirements for such contributions to be realized and problems that inhibit a contribution or even have a negative impact on sustainability. In total, nine contributions, 27 conditions and 14 problems have been described in the reviewed literature (Table 2). In each article, one or more of these aspects are present. The connection between the three aspects and the characterization of the categories is presented schematically in Figure 4. In the following sections, the characteristics of all categories will be described.

Table 2. Contributions, conditions and problems described in the literature and the numbers of papers that name them, in sum and per category.

\begin{tabular}{|c|c|c|c|c|c|}
\hline \multirow{2}{*}{ Contribution/Condition/Problem } & \multicolumn{5}{|c|}{ Number of papers } \\
\hline & $\Sigma$ & I & II & III & IV \\
\hline \multicolumn{6}{|l|}{ Contribution } \\
\hline Reduction of greenhouse gas emissions & 21 & 3 & 18 & - & - \\
\hline Sustainable production of commodities & 18 & 6 & 12 & - & - \\
\hline General contribution & 14 & 2 & 12 & - & - \\
\hline Sustainable society & 9 & - & 9 & - & - \\
\hline Reduction of negative environmental impact & 7 & 3 & 4 & - & - \\
\hline Sustainable use of resources & 7 & - & 7 & - & - \\
\hline Sustainable fertilizers & 5 & 1 & 4 & - & - \\
\hline Sustainable energy & 4 & 1 & 3 & - & - \\
\hline Biodiversity & 3 & 1 & 2 & - & - \\
\hline Social equity & 3 & - & 3 & - & - \\
\hline Possible contribution & 10 & - & - & 10 & - \\
\hline \multicolumn{6}{|l|}{ Condition } \\
\hline Sustainable biomass production & 18 & - & 14 & 4 & - \\
\hline Assessment of production chains and impact & 13 & - & 11 & 1 & 1 \\
\hline Efficient use of biomass resources: all components and by-products & 13 & - & 12 & 1 & - \\
\hline Assessment of sustainability or application of criteria & 12 & - & 10 & 1 & 1 \\
\hline Sustainability central element in bioeconomy & 12 & - & 7 & 5 & - \\
\hline Efficient use of biomass resources: best application of resources & 11 & - & 8 & 3 & - \\
\hline Sustainable production chains & 10 & - & 9 & 1 & - \\
\hline Research and Development: innovative products & 10 & - & 8 & 2 & - \\
\hline Efficient land use & 7 & - & 5 & 1 & 1 \\
\hline Public participation & 6 & - & 3 & 2 & 1 \\
\hline Assessment of best biomass sources & 5 & - & 5 & - & - \\
\hline Assessment of efficient biomass use & 5 & - & 5 & - & - \\
\hline Improved agricultural practices & 5 & - & 4 & 1 & - \\
\hline Research and Development: sustainability of bioeconomy & 5 & - & 4 & 1 & - \\
\hline
\end{tabular}


Table 2. Cont.

\begin{tabular}{llcccc}
\hline \multirow{2}{*}{ Contribution/Condition/Problem } & \multicolumn{5}{c}{ Number of papers } \\
\cline { 2 - 6 } & $\boldsymbol{\Sigma}$ & I & II & III & IV \\
\hline Condition & & & & & \\
\hline Assessment and management of invasion risks and effects & 4 & - & - & 1 & 3 \\
Regulation: sustainability standards for resources & 4 & - & 4 & - & - \\
Assessment of policy impact & 3 & - & 1 & - & 2 \\
Biodiversity conservation & 3 & - & 2 & - & 1 \\
Incentives: sustainable land use & 3 & - & 3 & - & - \\
International cooperation & 3 & - & 1 & 1 & 1 \\
Reduction of greenhouse gas emissions & 3 & - & - & 2 & 1 \\
Sustainable land use & 3 & - & 2 & - & 1 \\
Assessment of biomass availability & 2 & - & 2 & - & - \\
Assessment of land use efficiency & 2 & - & 2 & - & - \\
Incentives: industrial application of biomass & 2 & - & 2 & - & - \\
Socially responsible biomass production & 2 & - & - & 2 & - \\
Sustainable forest management & 2 & - & 2 & - & - \\
\hline Problem & & & & & \\
\hline Competition for land & 24 & - & 14 & 6 & 4 \\
Competition for resources & 21 & - & 15 & 3 & 3 \\
Reduction of emissions unclear & 16 & - & 11 & 3 & 2 \\
Contribution to sustainable development questionable & 13 & - & 3 & 2 & 8 \\
Negative impacts on water systems & 13 & - & 8 & 3 & 2 \\
Negative impacts on the environment & 12 & - & 7 & 3 & 2 \\
Negative impacts on soils & 10 & - & 7 & 2 & 1 \\
Negative impacts on habitats and biodiversity & 9 & - & 6 & 2 & 1 \\
Risks posed by invasive species & 7 & - & 1 & 2 & 4 \\
Agricultural intensification & 6 & - & 3 & 1 & 2 \\
Social concerns & 5 & - & 2 & 1 & 2 \\
Risks posed by new techniques and unknown long termyyyyyyyyy Economic feasibility & 5 & - & 2 & - & 3 \\
Health risks & 4 & - & 2 & - & 2 \\
\hline & 2 & - & - & 1 & 1 \\
\hline
\end{tabular}

The categories are indicated with roman numerals. If a contribution, condition or problem is not mentioned in any article of a certain category, the symbol "-" is applied.

Each publication has been allocated to one of the categories. The first category contains 12 papers describing the contributions and positive impacts of the bioeconomy on sustainability. The second category, containing 53 papers, is the largest. These publications focus on various conditions that have to be met in order to realize contributions to sustainability and avoid certain problems. The third category comprises 10 papers arguing that a contribution to sustainability is possible, but not necessarily reached. These papers also describe the risks of the development of a bioeconomy in the form of problems and possible negative consequences. The last category contains 12 papers focusing on the negative impacts of the bioeconomy. Some name conditions without stating that they will ensure sustainability, but most only discuss problems of the bioeconomy with regard to sustainability. In the following sections, we describe the categories in more detail. 
Figure 4. Schematic presentation of the four categories of papers, based on the relation between contributions, conditions and problems.

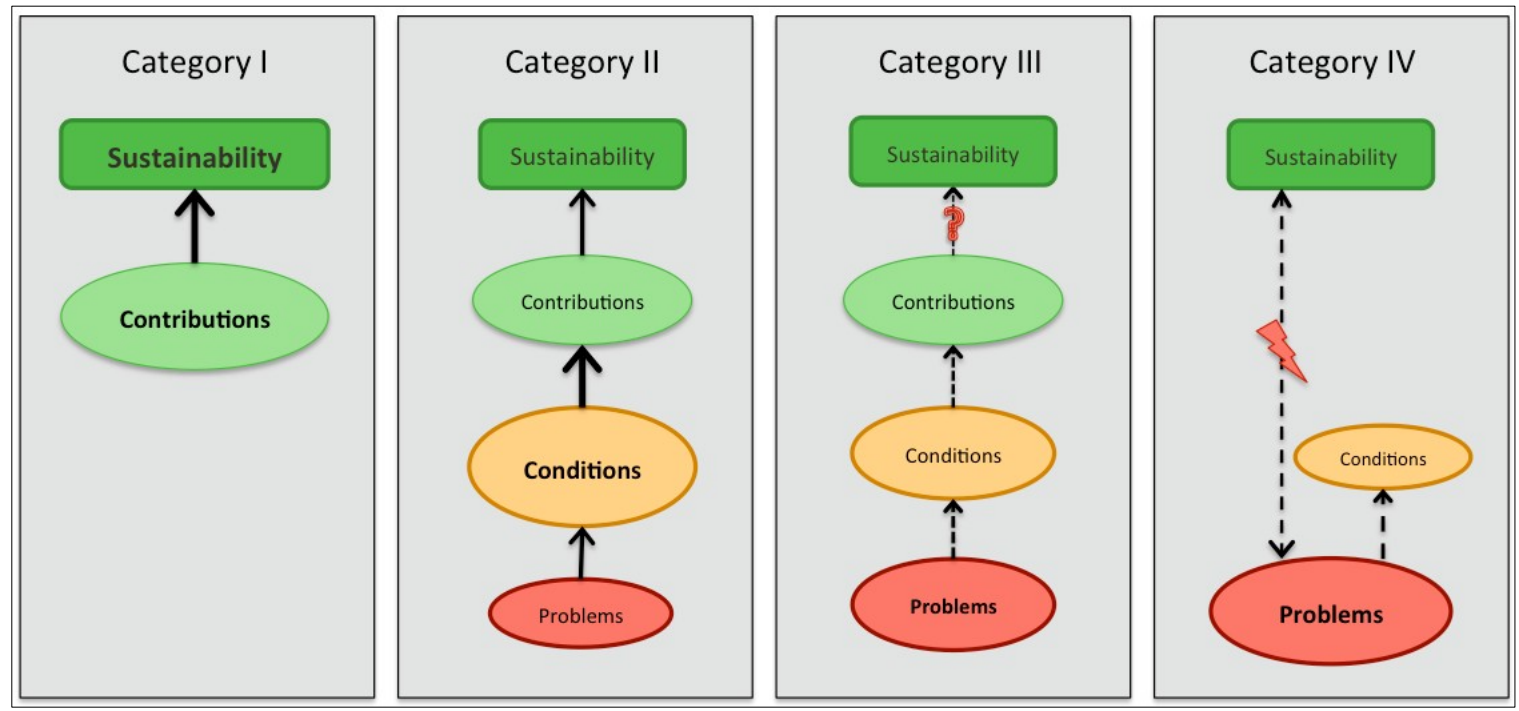

\subsubsection{Category I: Sustainability as an Inherent Characteristic}

The papers combined in this first category consider sustainability as an implicit result of the bioeconomy. Developments leading towards a bioeconomy also contribute to sustainability and are regarded as positive. Some speak of the bioeconomy as if it was self-evidently sustainable, for example referring to the use of renewable resources, which are the basis of the bioeconomy, as sustainable [31,68,88,101,102]. Most papers name specific contributions of the bioeconomy to sustainability, which are shown in Table 2. The contributions range from sustainable products, such as fertilizers, energy or commodities in general $[31,35,36,43,47,88,91,95,101,102]$, to physical and ecological benefits, such as the reduction of greenhouse gas emissions and other negative environmental impacts $[36,43,47,88]$. Both Chen [35] and Hardy [43] indicate that the bioeconomy generally contributes to sustainability.

\subsubsection{Category II: Conditional Benefits}

The second category comprises papers arguing that the bioeconomy is beneficial for sustainability under certain circumstances. They are generally supportive of a development toward a bioeconomy and argue that it will contribute to sustainability, if certain preconditions are met. Most papers name sustainability, or contributions to sustainability, as positive or desired outcomes of the development towards a bioeconomy. Some mention problems connected to the bioeconomy and especially biofuels, but they subsequently describe measures or strategies to avoid these problems. As in the first category, some papers assume that renewable resources are generally sustainable $[6,28,53,78,87,93,97]$. Furthermore, 14 papers argue that sustainability should be a goal of the transition to a bioeconomy $[4,6,19,46,60,61,64,70,73,75,78,86,93,100]$, and seven state that it should be a central element in a bioeconomy $[4,6,33,49,50,58,85]$. A wide range of conditions is described. Some conditions directly regard sustainable production systems (named in 31 papers), such as sustainable biomass production, sustainable production chains or sustainable land use. Papers refer to the necessity to reduce environmental impact, increase sustainability in agricultural production and ensure 
sustainable cultivation and harvesting practices. Other papers claim that efficient use of resources contributes to sustainability, for example efficient biomass or land use (named in 31 papers). Various papers argue that in order to be efficient, all components of a biomass resource should be used. In some papers, this refers to the use of all the different parts of crops; in others, more specific internal components are named, such as sugars, cellulose or lignin. Often, this efficient use is related to the manufacturing of a broad spectrum of products, in which the different feedstock fractions may serve as inputs for various supply chains. Another important aspect is the re-use or recycling of by-products, residues and waste streams. Often mentioned is, furthermore, the efficient use of biomass in terms of choosing the best application for each quantity of resource. Different feedstock types are more or less well suited for the broad spectrum of products envisaged for the bioeconomy. Choosing the most appropriate feedstock for each supply chain and realizing the maximum output from each quantity of biomass makes the resource use more efficient and is described as more sustainable. Other conditions regard strategic aspects (named in 24 papers), such as research and development and incentives or regulations of aspects considered important for sustainability, such as innovative products or stimulation of sustainability itself. Furthermore, international cooperation, public participation and biodiversity conservation are considered important conditions for sustainability (named in three, six and three papers, respectively). Many papers insist that in-depth assessments of various aspects of the bioeconomy have to be carried out (named in 46 papers), for example full assessments of individual production chains and their impact and specific sustainability or efficiency assessments. However, despite their plea for thorough assessments, these papers still remain generally positive about the impact of the bioeconomy on sustainability.

\subsubsection{Category III: Tentative Criticism}

The third category consists of publications that have more reservations regarding the bioeconomy. When it comes to sustainability, they consider a beneficial impact possible, but not self-evident. Apart from potential benefits, they also elaborate on problems for which they do not necessarily see solutions. Most of these papers consider sustainability important with regard to the bioeconomy. For example, they name it as goal or argue that it should be given a central role. However, while they appreciate sustainability, they are restrained in approving of all aspects of the bioeconomy. Several conditions and problems are mentioned, as shown in Table 2. The most important problem mentioned is the competition for land caused by an increased demand for biomass resources. This problem links up with the well-known "food $v s$. fuel" debate. It is mainly argued that the agricultural production of biomass for bioeconomic products (mainly biofuels) may be in competition with food and feed production [56,71,90]. The pressure on land is increasing through both biomass demand and population growth [56]. Both direct and indirect effects of land use change are described. Direct effects can be increased greenhouse gas emissions as a result of the clearing of forests for new production sites, but also resulting from different plantation methods of biofuel feedstock. Indirect effects are caused by the relocation of agriculture for food production to other land surfaces when the original land is used for new purposes within the bioeconomy [56,89]. However, not only competition for land with food production is an issue. Sheppard et al. [82] point out that, also, more marginal lands are used for biomass production. These marginal lands are often valuable for natural functions, such as biodiversity. 
Another problem described in the literature is that in some cases, bioeconomic production does not reduce greenhouse gas emissions, as expected, and sometimes, this effect remains unclear. Greenhouse gas emissions may result from land use changes, as described above, but also from energy use in the processing of biomass $[56,57,89]$. Other problems described in this category are, for example, negative impacts of biomass production on the surrounding environment and water systems. Examples are the destruction of natural ecosystems for new production areas, increased eutrophication, pests related to novel crops that may infect neighboring ecosystems and high demand for water, resulting in pressure on natural water systems and the ecosystems depending on them [56,57,69,82].

\subsubsection{Category IV: Negative Impact}

Papers in the fourth category consider the bioeconomy as disadvantageous for sustainability and do not expect any positive contributions. They are critical regarding expected benefits and focus on problems and risks (Table 2). Some formulate conditions without stating that they will ensure sustainability. Richardson [76] argues that the application of renewable resources is often presented as sustainable, and their exploitation is evermore intensified, while in his view, it does not ensure sustainability. Others point out that not all sustainability issues regarding the bioeconomy, such as biosecurity risks, are recognized sufficiently at the policy level, and at the same time, the proclaimed benefits for sustainability are yet unclear [81,83]. Marsden [63] criticizes that the bioeconomy paradigm has missing links when it comes to its integration in sustainable place-making. He argues that especially on a regional scale, the bioeconomy is often disconnected from specific aspects of ecosystems and landscapes and, furthermore, poorly embedded in regional social networks. Ponte [72] warns that in a bioeconomy, sustainability labelling may become more important than actually achieving sustainability, as is currently the case with fisheries. Other problems often mentioned by the papers in this category are competition for land, as described under Category III, and risks posed by invasive species. These concerns mainly relate to new crops used for biomass production that can become invasive and, consequently, threaten traditional production systems or natural ecosystems $[21,81,83]$. Insufficient management of invasion risks, for example, due to uncontrolled cultivation practices, can lead to the spread of the crop species themselves and their associated pests [40,81]. Barney et al. [21] point out that the crops envisioned for the bioeconomy will have a high invasion potential: they are required to be highly productive and, thus, harbor few pests and be competitive with other plant species, which are traits often found in invasive species. Furthermore, yearly harvesting and subsequent transportation may serve as an introduction pathway into other regions and ecosystems.

\subsubsection{Research Domains and Sustainability}

Figure 5 shows the research domains, as described in Section 3.1, in relation to the categories distinguished above. It stands out that the first two categories are dominated by the more technical domains of "Processing and Technology" and "Resources", while the third and fourth category are comprised of a greater variation of research domains. Especially the first category shows a prevalence of one research domain: 67\% of the papers deal with "Processing and Technology". In the second category, papers of all research domains are represented, but the largest groups are "Processing and Technology", "Resources", and "Environmental Impacts". While the research domains in the third 
category are very diverse, the most important domain in the fourth category is clearly the discussion of "Social Aspects" (42\%). Furthermore, it stands out that no papers discussing "Processing and Technology" of biomass focus on the negative impacts of the bioeconomy. At the same time, no papers of the research domain "Social Aspects" see sustainability as an inherent characteristic of the bioeconomy. Papers describing "Research and Development" and "Policy" agendas of the bioeconomy are distributed relatively equally over all categories. All five papers in the domain "Economics" describe a conditional contribution and are inclined to be positive about the sustainability of the bioeconomy. Papers writing about "Environmental Impacts" are represented in all categories, but 67\% consider a conditional contribution to sustainability, assuming that under certain preconditions, negative environmental impacts can be avoided.

Figure 5. Research domains regarding the bioeconomy per category.

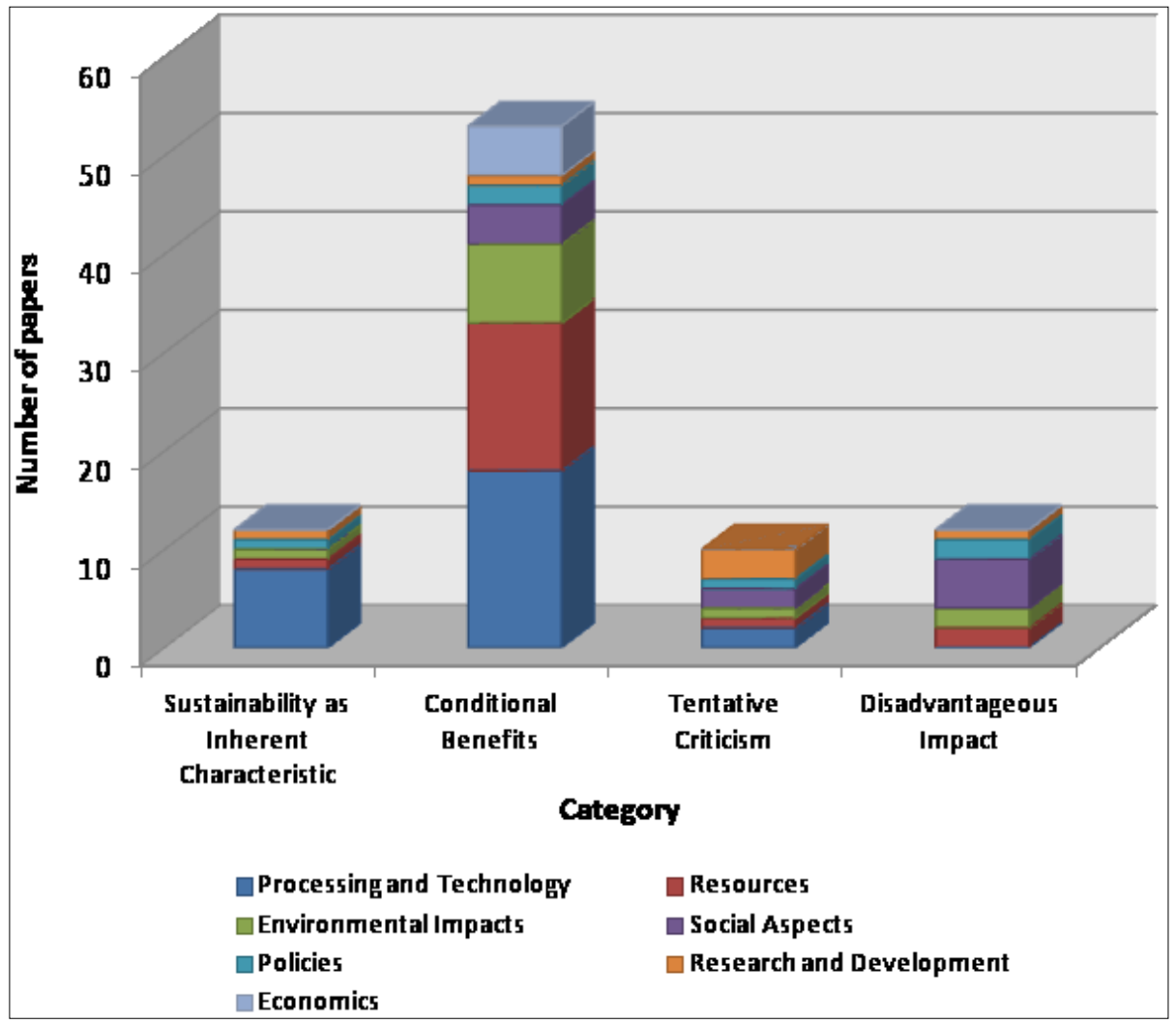

The four categories of publications identified in this review range from more positive to more negative views of the effect of the bioeconomy on sustainability. Clearly, the number of publications is highest in Category II, which might be characterized as mildly optimistic. When comparing the average years of publications per category, it appears that the number of critical papers has increased in recent years. However, an upward trend in recent years can be noticed for all categories. Papers from Category IV showed a publication peak in 2011. In that year, a special issue regarding the invasion risks of new crops in the bioeconomy was published in the journal "Current Opinion in Environmental Sustainability", from which six papers were reviewed here [38,40,75,81-83]. Three of the 12 publications in Category IV stem from this special issue and are mainly responsible for the peak of five papers in 2011. Nevertheless, also in 2012, four papers of Category IV were published, so an upward trend can be noticed. 


\subsection{Strategies for the Bioeconomy}

In addition to the above-described results, some general observations were made while reviewing the literature. They are concerned with various aspects of the actual development of the bioeconomy. These observations will be described in the following sections.

\subsubsection{Drivers of the Bioeconomy}

Throughout the reviewed literature, several drivers for the development of a bioeconomy, or reasons to engage in it, are named. The main driver discussed is the need to reduce our dependence on fossil resources (named in 69 papers). This aspect is of a three-fold nature. First of all, the availability of the resources is uncertain, and it is generally expected to decrease in the near future. Secondly, even if there are no immediate shortages, the remaining fossil fuel reserves are more difficult to reach. Extraction becomes more expensive and bears significant environmental risks, resulting in uncertainties about resource costs. Thirdly, it is pointed out that remaining reserves are often located in geopolitically unstable regions. These factors make it advantageous to find alternatives for fossil resources and, therefore, drive the development of the bioeconomy, where they are replaced with biogenic resources. The second driver discussed is the need to reduce greenhouse gas emissions or carbon footprints, due to the insights about their impact on the global climate system (named in 40 papers). Mostly, this driver is connected with the choice for renewable energy sources, amongst others bioenergy or biofuels. However, also the use of biogenic material in other supply chains reduces the consumption of fossil material and, thus, the release of carbon. Next to these reasons, which are mainly stimulated by the need to reduce the negative impacts of the use of fossil fuels, it is anticipated that the bioeconomy will create further benefits. It is, for example, expected to boost rural development and stimulate rural economies (named in 25 papers). It is assumed that a change of supply sources to biomass results in an increased demand for agricultural or forestry products. This increase of demand may stimulate rural economies and contribute to the social and economic revitalization of rural communities, including the creation of employment. Furthermore, farmers may take a larger role in supply chains by producing intermediate products and, thus, create additional income. Furthermore, other small suppliers of processing services might play an essential role. Other drivers named in the literature are the secure supply of energy and commodities (named in 23 papers), environmental concerns (named in 19 papers), expected economic benefits (named in 17 papers), an increasing demand for commodities in general and sustainable products in particular (each named in 14 papers), sustainability (named in seven papers) and food security (named in five papers).

\subsubsection{Food Security, Marginal Land Use and Residual Biomass}

Next to conditions for the sustainability of the bioeconomy, some papers discuss general requirements that should be fulfilled. One is to ensure sufficient production of food. Using biomass resources for the production of biofuels and other raw materials for a bioeconomy is often criticized for its competition with food in the well-known "food vs. fuel" debate. In the papers reviewed here, different suggestions are made on how to avoid this competition. Some argue that biomass for fuel or material applications should be derived from non-food crops, therefore avoiding direct competition for 
the same resource $[51,65,79]$. Others suggest that the amount of land required for sufficient food production should be determined and secured, using the remaining appropriate land surfaces for biomass production for the bioeconomy [52,57]. Again, others state that the total production should be increased $[79,86]$. Finally, some argue that land surfaces not used or unusable for food production should be used for the production of non-food biomass production [34,65,97]. Generally, the land availability and land use competition is described by many as a problem or even the limiting factor for the development of a bioeconomy [5,19,22,24,29,33,34,44,51,52,56,57,63-65,71,75,77,81,82,84,89,90,93], and the competition with food production is the most described example. An often-suggested solution for the land use competition is the use of marginal land surfaces for non-food biomass production $[33,34,52,65,81,97]$, avoiding the competition with traditional food production. However, some criticize that also the use of marginal lands is a land use change and may have negative impacts, for example on biodiversity $[75,81,82]$. An alternative opted for by some papers is the use of biomass residues, for example the fibrous, non-productive parts of food crops, other agricultural residues or biogenic waste streams from industrial production or private use $[33,44,47,51,56,70,93,99]$. New technologies are expected to enable the use of, for example, residual lignocellulosic biomass. The use of such residues makes it possible to re-use materials that would otherwise be waste as input for new production chains, resulting in a "circular" use of resources. Next to the use of biogenic waste, it is also considered important to use all components of any amount of resources, as described in Section 3.2.2.

\subsubsection{Regional Scale}

One of the most frequently mentioned reasons or drivers for the bioeconomy is rural development, as mentioned above. Next to the expected advantages from rural revitalization, various papers discuss advantages of developing bioeconomies on a regional scale. Local or decentralized production and processing may save transportation costs and related greenhouse gas emissions and enable a local reuse of by-products [28,31,70,97]. Furthermore, it enables small-scale production, which is expected to be more flexible and stimulate local economic development $[28,31,57,58,70,93]$. This economic benefit and concentration of incomes to a limited region may furthermore foster social benefits through local employment and a fairer distribution of incomes, and, thus, more equity [31,57,59]. Finally, focusing on specific regions allows for the adaptation to regional characteristics, such as local feedstock. Furthermore, the local knowledge of stakeholders, for example farmers, can provide significant advantages and add to the knowledgebase for the bioeconomy [30,37,58,59,63,80].

\subsubsection{Integrated Approach}

As described in Section 3.1, the bibliographic analysis confirmed that the sustainability of the bioeconomy is a multi-disciplinary field. Various papers emphasize this and furthermore argue that integrated approaches to solve problems regarding the bioeconomy are required. It is acknowledged that the concept of the bioeconomy and related issues are multidimensional $[75,80,90,93]$. Some papers therefore argue that an integrated or system-based approach is required to understand and address, for example, varying interests and interrelationships of actions and problems [6,75,80,97]. Other papers plead for collaboration between the various disciplines and lines of research involved in the 
bioeconomy (e.g., agro-ecological research, green and white biotechnology, biofuel research, biology and social science) [75,80,90,97]. Raghu et al. [75] state that multiple perspectives should be considered, avoiding simplistic "for" or "against" claims by different disciplines [75] (p. 21). In addition to integration between disciplines, papers argue for collaboration with a variety of stakeholders, bridging the gap between science and society. This way, science can link up with societal infrastructure and public interest. Public participation is described as a requirement, but also as an opportunity for a joint production of knowledge $[6,70,75,80,90]$. Finally, it is stated by three papers that international cooperation is required in order to realize sustainability in the bioeconomy $[53,81,82]$.

\section{Discussion}

This paper provides an overview of the scientific debate on the bioeconomy, focusing on how scientific literature relates the bioeconomy to sustainability. Both bioeconomy and sustainability are considered multi-disciplinary concepts, and therefore, a broad approach has been taken to include literature from various fields. The wide range of journals with relevant contributions confirms this assumption, and the growth in the number of papers published in the last decade indicates the increasing importance and contemporary nature of this field.

\subsection{The Undefined Position of Sustainability in Current Research}

A majority of the papers consider the relationship between the bioeconomy and sustainability as generally positive ( $75 \%$, Category I and II). The positive contributions discussed vary from general steps towards a more sustainable economy to specific physical or environmental benefits. Various papers speak of a "sustainable bioeconomy", without clarifying whether there may also be an un-sustainable bioeconomy. In some cases, the sustainable bioeconomy is mentioned as a goal; in others, the bioeconomy is presented as if it is self-evidently sustainable. Furthermore, in some papers, sustainability is reduced to the choice of renewable instead of fossil resources. They argue that the replacement of fossil materials with biomass automatically contributes to sustainability. However, Richardson [76] and Wellisch et al. [6] contradict precisely this argument, stating, for example, that "...sustainability is not just about renewability or only about the environment or only about GHG emissions." (i.e., greenhouse gas) [6] (p. 284). According to Wellisch et al. [6], the bioeconomy has the potential to create various positive outcomes and contribute to sustainability, but "...sustainable design must be deliberately planned and assessed." [6] (p. 283). This points to the importance of giving sustainability a central place in the development of the bioeconomy and considering sustainability in future bioeconomy research.

\subsection{The Hegemony of Optimism}

The papers considering the bioeconomy as generally positive for sustainability are dominated by technical research. Often, the expected contribution underpins the research itself, for example regarding technology developments or crop assessments. However, although technical papers suggest that the bioeconomy is quite sustainable, the more critical publications show that this is not necessarily true. Even though a majority of publications presents a positive picture, most papers (86\%) 
acknowledge problems regarding the impact of bioeconomic activities on sustainability. The discussed problems range from uncertainties and general concerns to measurable negative impacts. Doubts regarding the very goals of the bioeconomy are put forward, stating that the emission reduction promised by biomass is not always realized in practice and that sustainability is not reached. Concerns about uncertainties regarding the impact of invasive species, new technologies, economic feasibility and social impacts are raised. Measureable impacts on mainly the natural environment are discussed, with a special focus on the competition for land and resources. While some papers regard the bioeconomy critically because of these negative impacts, most remain positive despite describing problems. They discuss possible interventions and conditions for a positive outcome and generally still assume that the bioeconomy will contribute to sustainability.

\subsection{Conditions for a Sustainable Bioeconomy}

The conditions for a sustainable bioeconomy that were identified can be organized on the basis of whether they address what one needs to know or do to be sustainable (knowledge or practical application) and whether they restrict or stimulate bioeconomic activities (restrictive or stimulating). For example, some suggest that we have to find out more about sustainability and efficiency of processes through assessments, whereas others suggest that we need efficient applications in practice to be sustainable. Figure 6 shows the listed conditions in a matrix with these two dimensions.

Figure 6. The matrix of conditions for a sustainable bioeconomy.

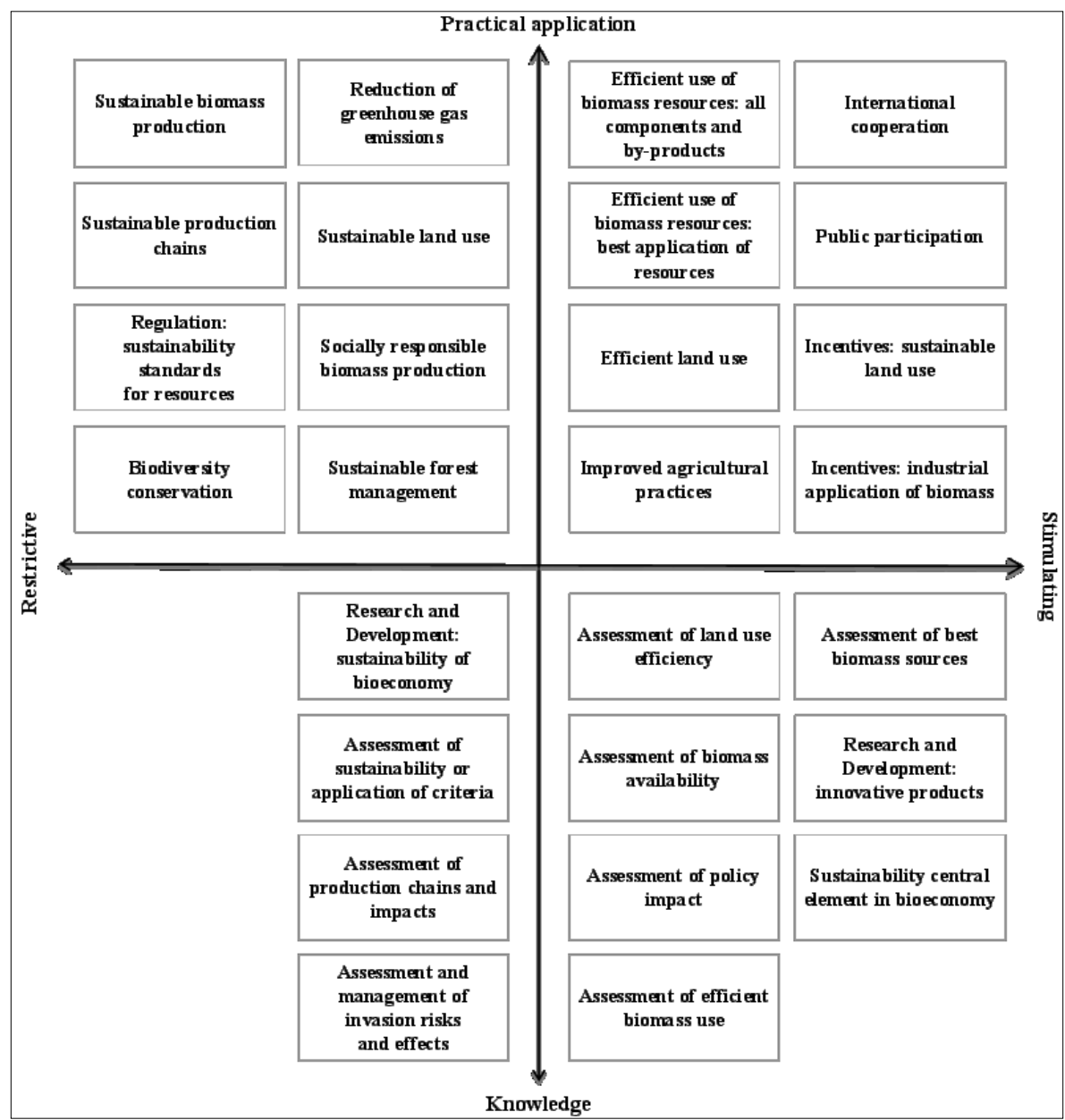


It shows that more conditions are concerned with applications than with knowledge. This could mean that there are already many insights on how the bioeconomy can be made more sustainable in practice. It could also indicate that the bioeconomy is initially addressed in a practical context. Insights gained from practical applications may then be important to improve theoretical understanding, which again calls for trans-disciplinary collaboration. Next to conditions regarding applications, the necessity for further analysis is, however, also clearly present. Many papers point out that assessments are required, analyzing, for example, sustainability in general or complete production chains. This shows that thorough analysis of sustainability aspects is considered important. Of course, it cannot be concluded that all aspects that have to be considered are named in the literature reviewed. However, the considerable number of publications analyzed and the variety of conditions described suggests that Figure 6 provides a good picture of the requirements currently recognized for sustainability in the bioeconomy.

\subsection{Sustainability from Side to Central Issue}

Looking at the drivers of the bioeconomy named in the literature, it stands out that while some are obviously related to issues of sustainability, such as climate change and its impact on the environment and human wellbeing, many do not directly regard issues of sustainability. The reduction of the dependence on fossil fuels, energy security or the expectation of economic benefits and rural development are, for example, issues that are mostly related to economic interests and not primarily sustainability concerns. It is therefore important to keep in mind the great variety of drivers of the development towards a bioeconomy when considering its sustainability. When striving for a bioeconomy, the contribution to sustainability should go hand in hand with achieving other goals and advantages. Research and policies should focus on how the various goals can be combined to create a bioeconomy that is as beneficial as possible, because otherwise, stakeholders with specific interests may dominate the developments, not necessarily contributing to the public good. An ecosystem services perspective may provide a useful framework to consider the use of biomass resources for various goals, provided that utilization is realized within the boundaries of sustainability (compare $[103,104]$ ).

\subsection{Decentralized Organization Fits Sustainability}

Rural development has been described as one of the most important drivers of the bioeconomy (see Section 3.3.1). Mostly, this relates to the increasing demand for biomass resources in general, which are mainly produced in rural areas. Moreover, it is discussed that benefits for rural communities can be promoted further by a decentralized organization of the bioeconomy. Other expected advantages are saving transportation costs and related emissions, enabling local reuse of by-products, flexible small-scale production that stimulates local economic development, social benefits of local employment, increased equity and adaptation to regional characteristics, taking into account local knowledge. Regarding sustainability, especially the reduced transportation emissions, the reuse of nutrients from by-products and the social benefits stand out. The total amount of carbon emissions from production through processing and use may be reduced, lowering the overall carbon footprint. Looking at the fact that many critical papers articulate doubts about the efficiency of greenhouse gas emission reduction by biomass use, decentralized organization could provide an advantage. Local economic 
development and the creation of employment possibilities contribute to social sustainability. Decentralized pre-treatment or even processing of biomass resources can play a significant role in this, enabling rural communities to be more than mere producers of primary resources. If more steps of the supply chains are undertaken in a decentralized way, incomes may be distributed more equally.

\subsection{Food vs. Fuel in the Short and Long Run}

On some aspects, the reviewed publications disagree or even contradict each other. In Section 3.3.2, we already mentioned the varying points of view on the use of marginal land and residual biomass. It seems that the costs and benefits of these approaches are not yet sufficiently clear and should be analyzed further. Regarding the food vs. fuel debate, arguments vary strongly. Some of the papers state that the high food prices in 2008, which are often used as the main argument in the debate, were not (primarily) caused by the competition with biofuel production [65,84], and especially in developing countries, the competition is considered harmless [52,64]. Nevertheless, $28 \%$ of publications consider land use competition a major problem. Some even argue that land availability will be the limiting factor for the development of the bioeconomy [5,19,29,71]. Research focusing on more effective production, processing and use is expected to defuse the conflict over land and resources. However, considering the growing importance of biomass resources and the ever growing demand for raw materials, it is argued by some that increased efficiency and the utilization of marginal lands and biomass residues will not suffice. Agricultural production for non-food applications will still be needed, and if all valuable land is reserved for food production and only the least productive parts of plants and residues are used for other supply chains, the demand cannot be met.

\subsection{The Plus of Trans-Disciplinarity}

Despite these contradictions in the literature, there appears to be relatively little debate about the characteristics of the bioeconomy itself. Most publications describe it as a broad field. The bioeconomy is currently mainly approached in a multi-disciplinary way: a broad array of research fields are represented, and the importance of other disciplines is recognized. However, many argue that more integrated, interdisciplinary or even trans-disciplinary approaches are required to address the issue appropriately. According to some papers, the integration of knowledge from various disciplines is crucial to achieve a sustainable bioeconomy, and also, policies regarding the bioeconomy should adopt a broader and more integrated scope $[6,75,80]$. Therefore, future research should not only recognize the breadth of the problem, but also incorporate insights from different fields and contribute to joint knowledge production. The impact of the bioeconomy on sustainability is addressed in various disciplines, as shown in this review. The discussion about the sustainability of the bioeconomy might actually provide a common focus for collaboration between disciplines and with societal stakeholders, but the varying visions of researchers have to be taken into account.

\subsection{Feasibility and Impact}

In general, it stands out that most reviewed papers were published very recently (within the last decade) and are dominated by technically focused research. These technical papers mainly assume that 
the bioeconomy will contribute to sustainability, in contrast to socio-economic papers that tend to be more skeptical. Critical research has on average been conducted in later years than papers assuming a positive impact of the bioeconomy. Taken together, these results suggest that scientific debate about the bioeconomy, specifically in relation to sustainability, is still at an early stage. Building upon the expectation that it will be beneficial, research is focused more on the technical feasibility of the bioeconomy, rather than on its actual impact. However, even though the emphasis of research may lie in technical issues, the discussion is already clearly broadening to include various external effects and conditions for sustainability.

\subsection{Elaborating Sustainability}

Sustainability of the bioeconomy is considered important by several of the publications reviewed. Seven point it out as one of the reasons to engage in the bioeconomy [6,27,70,71,77,81,97]; eleven argue that it should be a central element $[4,6,32,33,49,50,57,71,80,82,85]$, and 22 state that it should be the goal of the bioeconomy $[4,6,19,46,56,58,60,61,64,69-71,73,75,78,80,86,88,93,99-101]$. Wellisch et al. [6], however, point out that specific sustainability goals within the bioeconomy are often not clearly defined [6] (p. 282). Throughout our review, we found that sustainability is addressed regularly, but seldom defined or specified. It may therefore be necessary to elaborate specific sustainability goals of the development towards a bioeconomy, together with ways to ensure beneficial practices. The conditions and expected contributions presented in this review are a useful starting point for such considerations. This paper confirms some conclusions of other researchers addressing the effect of specific approaches within the bioeconomy on sustainability or the role of sustainability in policy documents regarding the bioeconomy, as mentioned in Section 1. De Meester et al. [5] and Wellisch et al. [6] conclude that biorefineries are potentially beneficial, but stress the importance of sustainability goals, assessments and regulations. These aspects are also represented in the various conditions named in the literature reviewed. Chisti [4] states that a bioeconomy can in principle be sustainable, but only if sustainability is a central objective of the economy itself. The varying views on the sustainability of the bioeconomy presented in this review confirm that a bioeconomy is not necessarily sustainable and that the consideration of sustainability is of great importance. Regarding policy documents, it has been concluded that sustainability plays a subordinate role in comparison to the goal of economic outputs and technological fixes for current problems [7-9]. It is argued that sustainability should be integrated more strongly in policy approaches for the bioeconomy. In many scientific publications, the importance of sustainability is recognized, but not necessarily a central topic. In research, as well as policy development, therefore, more attention should be paid to the impact of the bioeconomy on sustainability.

\section{Conclusions}

This review showed that visions about the relationship between bioeconomy and sustainability differ across scientific publications. Four categories of papers were identified that reflect the different visions on this relationship present in the literature, ranging from positive to negative: the assumption that sustainability is an inherent characteristic of the bioeconomy; the expectation of benefits under certain conditions; tentative criticism; and the expectation of a negative impact. The variety of 
problems and conditions shows that the bioeconomy cannot be considered self-evidently sustainable. Various risks and potential pitfalls have to be considered and avoided. Based on the results of this review, it can be concluded that there is considerable attention for sustainability in the scientific bioeconomy debate. Many publications state that sustainability should be a central topic on the research agendas for the bioeconomy or even be the goal of bioeconomic developments. Even though the bioeconomy might contribute to a more sustainable future in various ways, a positive impact is not self-evident. If sustainability is, however, considered a central goal of the bioeconomy, there may be a good chance of achieving a positive environmental and social impact, while ensuring economic growth through innovative products and the preservation of traditional sectors, such as food production. The economic outputs also may create social benefits. It is also important to consider the interrelationship between various sectors participating in a bioeconomy. By now, there seems to be a focus on discrepancies between sectors, mainly based on the competition for land and resources. However, especially cross-sectoral and interdisciplinary solutions are promising. Because bioeconomy research can be considered a multi-disciplinary field, stronger recognition and consideration of insights from other disciplines and stakeholders is necessary to build up a joint knowledgebase and tackle sustainability issues. To realize a contribution to sustainability, thorough assessments of different supply chains are required. It is important to analyze all activities within the bioeconomy, for example, using lifecycle analysis tools, to value their contribution to sustainability. However, such assessments should not only evaluate existing processes, but should also be used to choose the most beneficial applications for the future bioeconomy, so that an optimal contribution to sustainability can be reached. Throughout the reviewed literature, various positive expectations, requirements and potential pitfalls have been identified, but most publications consider only very few of these. Based on the findings of this review, we recommend approaching the bioeconomy systematically and in interdisciplinary or trans-disciplinary settings. The knowledge and insights from all related disciplines and stakeholders should be taken into account and translated into new research questions and policy interventions. Various disciplines already discuss the impact of the bioeconomy on sustainability, though visions of this relationship differ. The importance of sustainability is, however, broadly recognized and could thus provide common ground for collaboration and the development of a joint vision for the future bioeconomy.

\section{Acknowledgments}

The research leading to this review has received funding from the INTERREG IV A program (Deutschland-Nederland 2007-2013) of the European Territorial Co-operation, as part of the project "Groen Gas-Grünes Gas". It was conducted in the subproject "Decentralized Energy Landscapes Netherlands Germany” (DELaND).

\section{Author Contributions}

We declare that Swinda F. Pfau is the main author of this manuscript. All authors substantially contributed to the conception and design of this study, regularly reviewed the methodology and earlier versions of the manuscript and critically revised the final draft. Janneke E. Hagens furthermore provided a second opinion for the interpretation of data in cases of doubt. 


\section{Conflicts of Interest}

The authors declare no conflict of interest.

\section{References}

1. European Commission. Innovating for Sustainable Growth: A Bioeconomy for Europe; European Commission: Brussels, Belgium, 2012.

2. Organization for Economic Cooperation and Development (OECD). The Bioeconomy to 2030: Designing a Policy Agenda; OECD Publishing: Paris, France, 2009.

3. Bio-Economy Technology Platforms (BECOTEPS). White Paper "The European Bioeconomy in 2030-Delivering Sustainable Growth by Addressing the Grand Societal Challanges”; BECOTEPS: Brussels, Belgium, 2011.

4. Chisti, Y. A bioeconomy vision of sustainability. Biofuel. Bioprod. Bior. 2010, 4, 359-361.

5. De Meester, S.; Callewaert, C.; de Mol, E.; van Langenhove, H.; Dewulf, J. The resource footprint of biobased products: A key issue in the sustainable development of biorefineries. Biofuel. Bioprod. Bior. 2011, 5, 570-580.

6. Wellisch, M.; Jungmeier, G.; Karbowski, A.; Patel, M.K.; Rogulska, M. Biorefinery systems-Potential contributors to sustainable innovation. Biofuel. Bioprod. Bior. 2010, 4, $275-286$.

7. Birch, K.; Levidow, L.; Papaioannou, T. Sustainable capital? The neoliberalization of nature and knowledge in the European "knowledge-based bio-economy". Sustainability 2010, 2, 2898-2918.

8. McCormick, K.; Kautto, N. The Bioeconomy in Europe: An overview. Sustainability 2013, 5, 2589-2608.

9. Staffas, L.; Gustavsson, M.; McCormick, K. Strategies and policies for the bioeconomy and bio-based economy: An analysis of official national approaches. Sustainability 2013, 5, 2751-2769.

10. Fink, A. Conducting Research Literature Reviews, 3rd ed.; SAGE Publications, Inc.: Thousand Oaks, CA, USA, 2010; pp. 272.

11. Stechemesser, K.; Guenther, E. Carbon accounting: A systematic literature review. J. Clean. Prod. 2012, 36, 17-38.

12. Tress, G.; Tress, B.; Fry, G. Clarifying integrative research concepts in landscape ecology. Landsc. Ecol. 2004, 20, 479-493.

13. Web of Science. Available online: http://www.thomsonreuters.com/web-of-science (accessed on 23 January 2014).

14. Scirus. Available online: http://www.scirus.com (accessed on 23 January 2014).

15. ScienceDirect. Available online: http://www.sciencedirect.com (accessed on 23 January 2014).

16. EconLit. Available online: http://www.aeaweb.org/econlit (accessed on 23 January 2014).

17. IBSS. Available online: http://search.proquest.com/ibss (accessed on 23 January 2014).

18. ATLAS.ti. Available online: http://www.atlasti.com/index.html (accessed on 23 January 2014).

19. Alvarenga, R.A.F.; Dewulf, J.; van Langenhove, H. A new natural resource balance indicator for terrestrial biomass production systems. Ecol. Indicat. 2013, 32, 140-146. 
20. Arancibia, F. Challenging the bioeconomy: The dynamics of collective action in Argentina. Technol. Soc. 2013, 35, 79-92.

21. Barney, J.N.; Mann, J.J.; Kyser, G.B.; DiTomaso, J.M. Assessing habitat susceptibility and resistance to invasion by the bioenergy crops switchgrass and Miscanthus $\times$ giganteus in California. Biomass Bioenergy 2012, 40, 143-154.

22. Bartolini, F.; Viaggi, D. An analysis of policy scenario effects on the adoption of energy production on the farm: A case study in Emilia-Romagna (Italy). Energy Policy 2012, 51, 454-464.

23. Becker, D.R.; Skog, K.; Hellman, A.; Halvorsen, K.E.; Mace, T. An outlook for sustainable forest bioenergy production in the Lake States. Energy Policy 2009, 37, 5687-5693.

24. Benning, C.; Pichersky, E. Harnessing plant biomass for biofuels and biomaterials. Plant J. 2008, 54, 533-535.

25. Bergmann, J.C.; Tupinambá, D.D.; Costa, O.Y.A.; Almeida, J.R.M.; Barreto, C.C.; Quirino, B.F. Biodiesel production in Brazil and alternative biomass feedstocks. Renew. Sustain. Energy Rev. 2013, 21, 411-420.

26. Binder, J.B.; Cefali, A.V.; Blank, J.J.; Raines, R.T. Mechanistic insights on the conversion of sugars into 5-hydroxymethylfurfural. Energy Environ. Sci. 2010, 3, 765-771.

27. Boehlje, M.; Bröring, S. The increasing multifunctionality of agricultural raw materials: Three dilemmas for innovation and adoption. Int. Food Agribus. Manag. Rev. 2011, 14, 1-16.

28. Bramsiepe, C.; Sievers, S.; Seifert, T.; Stefanidis, G.D.; Vlachos, D.G.; Schnitzer, H.; Muster, B.; Brunner, C.; Sanders, J.P.M.; Bruins, M.E.; et al. Low-cost small scale processing technologies for production applications in various environments-Mass produced factories. Chem. Eng. Process. 2012, 51, 32-52.

29. Brehmer, B.; Struik, P.C.; Sanders, J. Using an energetic and exergetic life cycle analysis to assess the best applications of legumes within a biobased economy. Biomass Bioenergy 2008, 32, $1175-1186$.

30. Brehmer, B.; Sanders, J. Assessing the current Brazilian sugarcane industry and directing developments for maximum fossil fuel mitigation for the international petrochemical market. Biofuel. Bioprod. Bior. 2009, 3, 347-360.

31. Bruins, M.E.; Sanders, J.P.M. Small-scale processing of biomass for biorefinery. Biofuel. Bioprod. Bior. 2012, 6, 135-145.

32. Brunori, G. Biomass, biovalue and sustainability: Some thoughts on the definition of the bioeconomy. EuroChoices 2013, 12, 48-52.

33. Centi, G.; Lanzafame, P.; Perathoner, S. Analysis of the alternative routes in the catalytic transformation of lignocellulosic materials. Catal. Today 2011, 167, 14-30.

34. Charlton, A.; Elias, R.; Fish, S.; Fowler, P.; Gallagher, J. The biorefining opportunities in Wales: Understanding the scope for building a sustainable, biorenewable economy using plant biomass. Chem. Eng. Res. Des. 2009, 87, 1147-1161.

35. Chen, S. Industrial biosystems engineering and biorefinery systems. Chin. J. Biotechnol. 2008, 24, 940-945.

36. Cichocka, D.; Claxton, J.; Economidis, I.; Högel, J.; Venturi, P.; Aguilar, A. European Union research and innovation perspectives on biotechnology. J. Biotechnol. 2011, 156, 382-391. 
37. De Jong, E.; Higson, A.; Walsh, P.; Wellisch, M. Product developments in the bio-based chemicals arena. Biofuel. Bioprod. Bior. 2012, 6, 606-624.

38. Dubois, J.-L. Requirements for the development of a bioeconomy for chemicals. Curr. Opin. Environ. Sustain. 2011, 3, 11-14.

39. Dusselier, M.; van Wouwe, P.; Dewaele, A.; Makshina, E.; Sels, B.F. Lactic acid as a platform chemical in the biobased economy: The role of chemocatalysis. Energy Environ. Sci. 2013, 6, 1415-1442.

40. Ferdinands, K.; Virtue, J.; Johnson, S.B.; Setterfield, S.A. "Bio-insecurities": Managing demand for potentially invasive plants in the bioeconomy. Curr. Opin. Environ. Sustain. 2011, 3, 43-49.

41. FitzPatrick, M.; Champagne, P.; Cunningham, M.F.; Whitney, R.A. A biorefinery processing perspective: Treatment of lignocellulosic materials for the production of value-added products. Bioresour. Technol. 2010, 101, 8915-8922.

42. Galvez, A.; Sinicco, T.; Cayuela, M.L.; Mingorance, M.D.; Fornasier, F.; Mondini, C. Short term effects of bioenergy by-products on soil $\mathrm{C}$ and $\mathrm{N}$ dynamics, nutrient availability and biochemical properties. Agric. Ecosyst. Environ. 2012, 160, 3-14.

43. Hardy, R.W.F. The Bio-based Economy; Janick, J., Whipkey, A., Eds.; ASHS Press: Alexandria, VA, USA, 2002; pp. 11-16.

44. Hatti-Kaul, R. Biorefineries - A path to sustainability? Crop Sci. 2010, 50, S152-S156.

45. Hoefnagels, R.; Banse, M.; Dornburg, V.; Faaij, A. Macro-economic impact of large-scale deployment of biomass resources for energy and materials on a national level-A combined approach for the Netherlands. Energy Policy 2013, 59, 727-744.

46. Huang, H. Plant diversity and conservation in China: Planning a strategic bioresource for a sustainable future. Bot. J. Linn. Soc. 2011, 166, 282-300.

47. Jenkins, T. Toward a biobased economy: Examples from the UK. Biofuel. Bioprod. Bior. 2008, 2, 133-143.

48. Jordan, N.; Boody, G.; Broussard, W.; Glover, J.D.; Keeney, D.; McCown, B.H.; McIsaac, G.; Muller, M.; Murray, H.; Neal, J.; et al. Sustainable development of the agricultural bio-economy. Science 2007, 316, 1570-1571.

49. Junginger, M.; Bolkesjø, T.; Bradley, D.; Dolzan, P.; Faaij, A.; Heinimö, J.; Hektor, B.; Leistad, Ø.; Ling, E.; Perry, M.; et al. Developments in international bioenergy trade. Biomass Bioenergy 2008, 32, 717-729.

50. Keegan, D.; Kretschmer, B.; Elbersen, B.; Panoutsou, C. Cascading use: A systematic approach to biomass beyond the energy sector. Biofuel. Bioprod. Bior. 2013, 7, 193-206.

51. Keijsers, E.R.P.; Yılmaz, G.; van Dam, J.E.G. The cellulose resource matrix. Carbohydr. Polymer. 2013, 93, 9-21.

52. Kgathi, D.L.; Mfundisi, K.B.; Mmopelwa, G.; Mosepele, K. Potential impacts of biofuel development on food security in Botswana: A contribution to energy policy. Energy Policy 2012, 43, 70-79.

53. Kircher, M. The transition to a bio-economy: National perspectives. Biofuel. Bioprod. Bior. 2012, 6, 240-245.

54. Kitchen, L.; Marsden, T. Constructing sustainable communities: A theoretical exploration of the bio-economy and eco-economy paradigms. Local Environ. 2011, 16, 753-769. 
55. Krigstin, S.; Hayashi, K.; Tchórzewski, J.; Wetzel, S. Current inventory and modelling of sawmill residues in Eastern Canada. Forest. Chron. 2012, 88, 626-635.

56. Landeweerd, L.; Surette, M.; van Driel, C. From petrochemistry to biotech: A European perspective on the bio-based economy. Interface Focus 2011, 1, 189-195.

57. Langeveld, J.W.A.; Dixon, J.; Jaworski, J.F. Development perspectives of the biobased economy: A review. Crop Sci. 2010, 50, S-142-S-151.

58. Lehtonen, O.; Okkonen, L. Regional socio-economic impacts of decentralised bioeconomy: A case of Suutela wooden village, Finland. Environ. Dev. Sustain. 2013, 15, 245-256.

59. Levidow, L.; Birch, K.; Papaioannou, T. Divergent paradigms of European agro-food innovation: The knowledge-based bio-economy (KBBE) as an R\&D agenda. Sci. Technol. Human Values 2012, 38, 94-125.

60. Liu, S. Woody biomass: Niche position as a source of sustainable renewable chemicals and energy and kinetics of hot-water extraction/hydrolysis. Biotechnol. Adv. 2010, 28, 563-582.

61. Liu, S.; Lu, H.; Hu, R.; Shupe, A.; Lin, L.; Liang, B. A sustainable woody biomass biorefinery. Biotechnol. Adv. 2012, 30, 785-810.

62. Lorenz, P.; Zinke, H. White biotechnology: Differences in US and EU approaches? Trends Biotechnol. 2005, 23, 570-574.

63. Marsden, T. Sustainable place-making for sustainability science: The contested case of agri-food and urban-Rural relations. Sustain. Sci. 2013, 8, 213-226.

64. Mathews, J.A. Biofuels, climate change and industrial development: Can the tropical South build 2000 biorefineries in the next decade? Biofuel. Bioprod. Bior. 2008, 2, 103-125.

65. Mathews, J.A. From the petroeconomy to the bioeconomy: Integrating bioenergy production with agricultural demands. Biofuel. Bioprod. Bior. 2009, 3, 613-632.

66. Müller, M.M.; Kügler, J.H.; Henkel, M.; Gerlitzki, M.; Hörmann, B.; Pöhnlein, M.; Syldatk, C.; Hausmann, R. Rhamnolipids-Next generation surfactants? J. Biotechnol. 2012, 162, 366-380.

67. Murray, P.M.; Moane, S.; Collins, C.; Beletskaya, T.; Thomas, O.P.; Duarte, A.W.F.; Nobre, F.S.; Owoyemi, I.O.; Pagnocca, F.C.; Sette, L.D.; et al. Sustainable production of biologically active molecules of marine based origin. New Biotechnol. 2013, 30, 839-850.

68. Navia, R.; Mohanty, A.K. Resources and waste management in a bio-based economy. Waste Manag. Res. 2012, 30, 215-216.

69. Nuss, P.; Gardner, K.H. Attributional life cycle assessment (ALCA) of polyitaconic acid production from northeast US softwood biomass. Int. J. Life Cycle Ass. 2013, 18, 603-612.

70. Osseweijer, P.; Landeweerd, L.; Pierce, R. Genomics in Industry: Issues of a bio-based economy. Genomics Soc. Policy 2010, 6, 26-39.

71. Paula, L.; Birrer, F. Including public perspectives in industrial biotechnology and the biobased economy. J. Agric. Environ. Ethics 2006, 19, 253-267.

72. Ponte, S. From fishery to fork: Food safety and sustainability in the "virtual" knowledge-based bio-economy (KBBE). Sci. Cult. 2009, 18, 483-495.

73. Preisig, H.A.; Wittgens, B. Thinking towards synergistic green refineries. Energy Procedia 2012, 20, 59-67. 
74. Puddister, D.; Dominy, S.W.J.; Baker, J.A.; Morris, D.M.; Maure, J.; Rice, J.A.; Jones, T.A.; Majumdar, I.; Hazlett, P.W.; Titus, B.D.; et al. Opportunities and challenges for Ontario's forest bioeconomy. Forest. Chron. 2011, 87, 468-477.

75. Raghu, S.; Spencer, J.L.; Davis, A.S.; Wiedenmann, R.N. Ecological considerations in the sustainable development of terrestrial biofuel crops. Curr. Opin. Environ. Sustain. 2011, 3, 15-23.

76. Richardson, B. From a fossil-fuel to a biobased economy: The politics of industrial biotechnology. Environ. Plann. C Govern. Policy 2012, 30, 282-296.

77. Rossi, A.M.; Hinrichs, C.C. Hope and skepticism: Farmer and local community views on the socio-economic benefits of agricultural bioenergy. Biomass Bioenergy 2011, 35, 1418-1428.

78. Gen Klaas, M.R.; Schöne, H. Direct, high-yield conversions of cellulose into biofuel and platform chemicals-on the way to a sustainable biobased economy. ChemSusChem 2009, 2, 127-128.

79. Sanders, J.; van der Hoeven, D. Opportunities for a bio-based economy in the Netherlands. Energies 2008, 1, 105-119.

80. Schmid, O.; Padel, S.; Levidow, L. The bio-economy concept and knowledge base in a public goods and farmer perspective. Bio Based Appl. Econ. 2012, 1, 47-63.

81. Sheppard, A.W.; Gillespie, I.; Hirsch, M.; Begley, C. Biosecurity and sustainability within the growing global bioeconomy. Curr. Opin. Environ. Sustain. 2011, 3, 4-10.

82. Sheppard, A.W.; Raghu, S.; Begley, C.; Genovesi, P.; de Barro, P.; Tasker, A.; Roberts, B. Biosecurity as an integral part of the new bioeconomy: A path to a more sustainable future. Curr. Opin. Environ. Sustain. 2011, 3, 105-111.

83. Sheppard, A.W.; Raghu, S.; Begley, C.; Richardson, D.M. Biosecurity in the new bioeconomy. Curr. Opin. Environ. Sustain. 2011, 3, 1-3.

84. Smyth, S.J.; Falck-Zepeda, J.B.; Gray, R.S.; Nassem, A.; Paarlberg, R.; Phillips, P.W.B.; Pray, C.E.; Savastano, S.; Scandizzo, P.; Scatasta, S.; et al. Policy recommendations from the 13th ICABR conference on the emerging bioeconomy. AgBioForum 2010, 13, 98-103.

85. Smyth, S.J.; Aerni, P.; Castle, D.; Demont, M.; Falck-Zepeda, J.B.; Paarlberg, R.; Phillips, P.W.B.; Pray, C.E.; Savastano, S.; Wesseler, J.H.H.; et al. Sustainability and the bioeconomy: Synthesis of key themes from the 15th ICABR conference. AgBioForum 2011, 14, 180-186.

86. Spiertz, H. Avenues to meet food security. The role of agronomy on solving complexity in food production and resource use. Eur. J. Agron. 2012, 43, 1-8.

87. Sultana, A.; Kumar, A. Ranking of biomass pellets by integration of economic, environmental and technical factors. Biomass Bioenergy 2012, 39, 344-355.

88. Tanksale, A.; Beltramini, J.N.; Lu, G.M. A review of catalytic hydrogen production processes from biomass. Renew. Sustain. Energy Rev. 2010, 14, 166-182.

89. Templer, R.; van der Wielen, L. Biorenewables, the bio-based economy and sustainability. Interface Focus 2011, 1, 187-188.

90. Ten Bos, R.; van Dam, J.E.G. Sustainability, polysaccharide science, and bio-economy. Carbohydr. Polym. 2013, 93, 3-8.

91. Tsiropoulos, I.; Cok, B.; Patel, M.K. Energy and greenhouse gas assessment of European glucose production from corn-A multiple allocation approach for a key ingredient of the bio-based economy. J. Clean. Prod. 2013, 43, 182-190. 
92. Vaaje-Kolstad, G.; Westereng, B.; Horn, S.J.; Liu, Z.; Zhai, H.; Sørlie, M.; Eijsink, V.G.H. An oxidative enzyme boosting the enzymatic conversion of recalcitrant polysaccharides. Science 2010, 330, 219-222.

93. Van Dam, J.E.G.; de Klerk-Engels, B.; Struik, P.C.; Rabbinge, R. Securing renewable resource supplies for changing market demands in a bio-based economy. Ind. Crop. Prod. 2005, 21, 129-144.

94. Vaneeckhaute, C.; Meers, E.; Michels, E.; Christiaens, P.; Tack, F.M.G. Fate of macronutrients in water treatment of digestate using vibrating reversed osmosis. Water Air Soil Pollut. 2012, 223, 1593-1603.

95. Vaneeckhaute, C.; Meers, E.; Ghekiere, G.; Accoe, F.; Tack, F.M.G. Closing the nutrient cycle by using bio-digestion waste derivatives as synthetic fertilizer substitutes: A field experiment. Biomass Bioenergy 2013, 55, 175-189.

96. Vaneeckhaute, C.; Meers, E.; Michels, E.; Buysse, J.; Tack, F.M.G. Ecological and economic benefits of the application of bio-based mineral fertilizers in modern agriculture. Biomass Bioenergy 2013, 49, 239-248.

97. Vanholme, B.; Desmet, T.; Ronsse, F.; Rabaey, K.; van Breusegem, F.; de Mey, M.; Soetaert, W.; Boerjan, W. Towards a carbon-negative sustainable bio-based economy. Front. Plant Sci. 2013, $4,1-17$.

98. Vitasari, C.R.; Meindersma, G.W.; de Haan, A.B. Water extraction of pyrolysis oil: The first step for the recovery of renewable chemicals. Bioresour. Technol. 2011, 102, 7204-7210.

99. Voll, A.; Marquardt, W. Benchmarking of next-generation biofuels from a process perspective. Biofuel. Bioprod. Bior. 2012, 6, 292-301.

100. Wesseler, J.; Aerni, P. Sustainability and the bioeconomy. AgBioForum 2011, 14, 94-96.

101. Zhang, J.; Babtie, A.; Stephanopoulos, G. Metabolic engineering: Enabling technology of a bio-based economy. Curr. Opin. Chem. Eng. 2012, 1, 355-362.

102. Zilberman, D.; Kim, E. The lessons of fermentation for the new bio-economy. AgBioForum 2011, 14, 97-103.

103. Carpenter, S.R.; Mooney, H.A.; Agard, J.; Capistrano, D.; DeFries, R.S.; Diaz, S.; Dietz, T.; Duraiappah, A.K.; Oteng-Yeboah, A.; Pereira, H.M.; et al. Science for managing ecosystem services: Beyond the Millennium Ecosystem Assessment. Proc. Natl. Acad. Sci. USA 2009, 106, 1305-1312.

104. Craig, R.K.; Ruhl, J.B. Governing for sustainable coasts: Complexity, climate change, and coastal ecosystem protection. Sustainability 2010, 2, 1361-1388.

(C) 2014 by the authors; licensee MDPI, Basel, Switzerland. This article is an open access article distributed under the terms and conditions of the Creative Commons Attribution license (http://creativecommons.org/licenses/by/3.0/). 